\title{
Panbacterial real-time PCR to evaluate bacterial burden in chronic wounds treated with Cutimed ${ }^{\mathrm{TM}}$ Sorbact $^{\mathrm{TM}}$
}

\author{
V. Gentili • S. Gianesini • P. G. Balboni • E. Menegatti • \\ A. Rotola $\cdot$ M. Zuolo $\cdot$ E. Caselli $\cdot$ P. Zamboni $\cdot$ \\ D. Di Luca
}

Received: 24 June 2011 / Accepted: 19 October 2011 / Published online: 19 November 2011

(C) The Author(s) 2011. This article is published with open access at Springerlink.com

\begin{abstract}
The impact of polymicrobial bacterial infection on chronic wounds has been studied extensively, but standard bacteriological analysis is not always sensitive enough. Molecular approaches represent a promising alternative to the standard bacteriological analysis. This work aimed to assess the usefulness of a panbacterial quantitative real-time PCR reaction to quantitate the total bacterial load in chronic wounds treated with Cutimed ${ }^{\mathrm{TM}}$ Sorbact ${ }^{\mathrm{TM}}$, a novel therapeutic approach based on hydrophobic binding of bacteria to a membrane. The results obtained by panbacterial real-time PCR on conserved sequences of the bacterial $16 \mathrm{~S}$ gene show that the bacterial burden significantly decreased in 10 out of 15 healing chronic wounds, and did not change in 5 out of 5 nonhealing chronic wounds. On the contrary, classical culture for $S$. aureus and P. aeruginosa, and real-time PCR for Bacteroides and Fusobacterium did not show any correlation with the clinical outcome. Our study also shows that quantification of chronic wounds by panbacterial real-time PCR is to be performed on biopsies and not on swabs. These results show that panbacterial real-time PCR is a promising and quick method of determining the total bacterial load in chronic wounds, and suggest that it might be an important biomarker for the prognosis of chronic wounds under treatment.
\end{abstract}

V. Gentili • P. G. Balboni · A. Rotola • E. Caselli • D. Di Luca $(\triangle)$ Department of Experimental and Diagnostic Medicine, University of Ferrara,

Via Borsari 46,

44121 Ferrara, Italy

e-mail: ddl@unife.it

S. Gianesini · E. Menegatti · M. Zuolo · P. Zamboni

Vascular Disease Center, University of Ferrara,

Ferrara, Italy

\section{Introduction}

Chronic wounds have the important characteristic that their healing time is not predictable and they may never heal, causing severe physical and emotional stress to patients. Major consequences are disability and decreased quality of life, but also a significant financial impact on the health care system, patients and their families.

Chronic wounds are colonized by a polymicrobial flora $[1,2]$, comprising commensal bacteria, such as staphylococci, streptococci, Pseudomonas spp., and coliform bacteria. Also anaerobic bacteria proliferate in the wound, owing to the combination of necrotic tissue and low oxygen tension [3]. The role of bacteria in wounds depends on their concentration, species composition, and host response [4, 5]. Contamination and colonisation by low concentrations of microbes are considered normal, and are not believed to inhibit healing [6]. However, critical colonisation and infection are associated with a significant delay in wound healing [7].

Clinical microbiology has focussed on determining the concentrations and identities of microbes associated with wound infection. Analysis of swabs or debridement tissue from chronic wounds, carried out by isolation on agar and biochemical characterisation, has several shortcomings. In fact, culture methods detect only about $1 \%$ of all bacteria present in chronic wounds [8], and it is not possible to isolate all bacterial species present in a specific wound.

Recently, several reports have strengthened the notion that the polymicrobial nature of infection, and the as yet undetermined interactions among colonizing bacteria, may play a major role in the lack of healing of chronic wounds $[9,10]$. Therefore, determination of the bacterial burden might be an important laboratory parameter. There is an increasing perception that the presence of $10^{5}$ or more 
bacterial cells per gram of tissue (determined by classic culture-based analysis) is a key determinant in delayed wound healing. However, quantitative cultural methods are limited in their aim to define a threshold value of significant bacterial burden. In fact, they depend on in vitro growth conditions and detect only viable and cultivable bacteria. To evaluate the significance of bacterial load in wound healing it is necessary to quantitate the full range of germs within a wound. Molecular methods are an attractive alternative to determining the bacterial burden, as they can identify even the non-cultivable micro-organisms $[10,11]$.

Real-time PCR, which allows precise quantification of bacterial load, has been used to detect and quantify specific pathogens in chronic wounds $[12,13]$, but it requires the use of specific reagents for each bacterial species of interest. An important development of real-time PCR has been the design of "universal" primers, focussed on the $16 \mathrm{~S}$ rRNA gene [14, 15], a highly conserved region among all bacteria. This approach determines the total bacterial burden with high sensitivity, rapid results, and detection of all bacteria, both aerobic and anaerobic.

The aim of this work was to assess the usefulness of panbacterial real-time PCR to determine the bacterial load in chronic wounds. The analysis was carried out in the course of a non-comparative, pilot clinical study designed to evaluate the efficacy of Cutimed ${ }^{\mathrm{TM}}$ Sorbact ${ }^{\mathrm{TM}}$ (BSN Medical, Hamburg, Germany), an innovative antimicrobial dressing for the management of chronic wounds. Cutimed ${ }^{\mathrm{TM}}$ Sorbact ${ }^{\mathrm{TM}}$ fibres are coated with a hydrophobic fatty acid that irreversibly binds to the bacterial surface, and mechanically removes bacteria from the wound at each dressing change [16-18] (www. cutimeduk.com/cutimed-sorbact.html). This mechanism of action can prevent or reduce treatment with antibiotics, avoiding several drug drawbacks, such as antibiotic resistance $[19,20]$.

\section{Materials and methods}

\section{Clinical study}

A non-comparative double-blind pilot study was carried out by the Vascular Disease Center (St. Anna Hospital, Ferrara). Ethics approval was obtained from the Ethics Committee of the University of Ferrara.

Nineteen consecutive patients (for a total of 20 wounds) affected by chronic arterial or venous leg ulcers were enrolled in the study and gave their written informed consent. Exclusion criteria were: malnutrition, systemic antibiotic treatment up to 2 weeks before the start of the study, immunosuppression and cortisone treatment.
Wounds were treated with a $0.9 \% \mathrm{NaCl}$ saline solution rinse, surgical debridement and application of Cutimed ${ }^{\mathrm{TM}}$ Sorbact ${ }^{\mathrm{TM}}$ (BSN Medical, Hamburg, Germany). Dressings were changed twice a week and the study was performed during a 4-week period. During dressing changes the wounds were rinsed with saline solution, and when necessary, PU foams, secondary covers and gold standard elasto-compression were used. Documentation of cases was performed using a standard wound documentation system and special individual case report forms, including an evaluation of wound conditions (wound size, amount of necrosis, granulation, fibrin and epithelialisation tissue, pain) and quality of life. Quality of life was assessed by the SF36 questionnaire, a standardised group of questions on general life conditions answered by the patient on a scale from 0 , being the worst condition, to 100 , the best condition.

Wound photographs were taken once a week. All specimens were transported to the laboratory under code to ensure the patients' privacy.

\section{Wound sampling}

Punch biopsies were taken at the beginning and end of the treatment with Cutimed $^{\mathrm{TM}}$ Sorbact ${ }^{\mathrm{TM}}$. Swabs were taken once a week during the dressing change. Tissue specimens, obtained aseptically and placed in a sterile tube containing $500 \mu \mathrm{L}$ of sterile phosphate buffered saline (PBS) were transported to the laboratory, where they were weighed, homogenised and lysed.

Wound swabbing was performed using the Cutimed ${ }^{\mathrm{TM}}$ Sorbact ${ }^{\mathrm{TM}}$ dressing to sample superficial wound fluid and tissue debris. Dressings were placed into a sterile tube containing $2 \mathrm{~mL}$ of sterile PBS and transported to the laboratory. Skin swabs from six healthy donors were used as controls.

\section{DNA extraction}

Biopsy and swab samples were incubated in $2 \mathrm{~mL}$ and $3 \mathrm{~mL}$ of lysis buffer $(0.6 \% \mathrm{SDS}, 10 \mathrm{mM}$ Tris, $1 \mathrm{mM}$ EDTA, $120 \mu \mathrm{g} / \mathrm{mL}$ proteinase $\mathrm{K}$ ) at $37^{\circ} \mathrm{C}$ overnight.

Genomic DNA was extracted by four treatments with phenol: chloroform: isoamyl alcohol (25:24:1). After isopropanol precipitation, DNA was centrifuged, washed with $75 \%$ ethanol, and re-suspended in $100 \mu \mathrm{L}$ of sterile water. DNA concentration was assessed by reading optical density at $260 \mathrm{~nm}$ using a spectrophotometer and by a second reading using the Qubit fluorometer (Invitrogen), thus avoiding incorrect reading because of the presence of RNA or proteins.

Purified DNA was stored at $-20^{\circ} \mathrm{C}$ until real-time PCR analysis. 
Bacterial strains

All bacterial strains were obtained from the American Type Culture Collection (ATCC, USA), including E. coli (ATCC 10536), S. aureus (ATCC 25923), P. aeruginosa (ATCC 15442), E. hirae (ATCC 541), S. agalactiae (ATCC 12344), B. subtilis (ATCC 6633), Bacteroides fragilis (ATCC 25285) and Fusobacterium necrophorum (ATCC 25286). Anaerobic bacteria were grown on CDC Anaerobe Agar with 5\% Sheep Blood plates and in BBL Cooked Meat Medium (Becton-Dickinson). Anaerobic conditions were created using the AnaeroGen sachet in the Anaerobic Jar (Oxoid), and assessed by the Anaerobic Indicator.

\section{Real-time PCR}

Quantitative real-time PCR was used to determine either the amount of total bacterial genomes with a panbacterial consensus set of primers and probe, as well as the amount of Bacteroides and Fusobacterium genomes with specific reactions.

The reactions were performed using the 7300 Applied Biosystems PCR equipment. Primers, probes and reaction conditions for panbacterial qPCR were as previously described by Yang et al. [21], except for modification of the reporter dye. Primer and probe sets for Bacteroides and Fusobacterium real-time PCR were designed on sequences deposited in GenBank (accession numbers CR626927 and FJ410389 respectively). Primers for Fusobacterium were: (forward) 5'-CCGCGCATTCCGTATGG -3', (reverse) 5'CGGGTAGGATCAGCCTGTTATC-3' and the probe was 5'-(6Fam) TCGTCGCTCAACGGATAAAAGCTACCCT (Tamra)-3'.

Primers for Bacteroides were: (forward) 5'-TTCAGGC TAGCGCCCATT-3', (reverse) 5'-GGAACTGAGA CACGGTCCAAAC-3', and the probe was 5'-(6Fam)CCAATATTCCTCACTGCTGCCTCCCGTA (Tamra)-3'.

The RNaseP eukaryotic gene was amplified using a 5'VIC-labelled and 3'-non-fluorescent (MGB, Applied Biosystems) probe. RNaseP gene was simultaneously quantified to calculate the number of eukaryotic cells present in the biopsy samples, as an internal positive control to ensure that all samples were suitable for amplification.

Amplifications were carried out in a $50-\mu \mathrm{L}$ total volume containing $25 \mu \mathrm{L}$ 2X TaqMan Universal Master Mix (Applied Biosystems), $2.5 \mu \mathrm{L}$ of primers and probes mix, $2.5 \mu \mathrm{L}$ of $20 \mathrm{X}$ RNaseP $\operatorname{mix}$ and $20-\mu \mathrm{L}$ template corresponding to $100 \mathrm{ng}$ of total DNA.

Concentrations of each primer and probe were, respectively, $900 \mathrm{nM}$ and $100 \mathrm{nM}$. The reaction conditions for all templates were: $10 \mathrm{~min}$ at $95^{\circ} \mathrm{C}$ for enzyme activation, 40 cycles with $15 \mathrm{~s}$ at $95^{\circ} \mathrm{C}$ for DNA denaturation and $60 \mathrm{~s}$ at $60^{\circ} \mathrm{C}$ for annealing and extension.
All samples were amplified in duplicate, and the average value was calculated.

Isolation of $S$. aureus and $P$. aeruginosa by culture methods

Briefly, 1/10 volume of biopsies and swabs were plated on Mannitol Salt agar plates (Oxoid) for the detection of $S$. aureus, and on Cetrimide agar plates (Oxoid) for the selection of $P$. aeruginosa. After 24 and $48 \mathrm{~h}$ incubation at $37^{\circ} \mathrm{C}$ respectively, the number of colony-forming units (CFU) of each micro-organism was counted for each plate.

Statistical analysis

Statistical analysis was conducted using the Stat View software package (SAS Institute, Cary, NC, USA). The data were analysed using the Mann-Whitney $U$ test. Statistical significance was assumed at $p<0.05$ (two-tailed).

\section{Results}

Clinical results

Responder patients were determined on the basis of a positive Margolis index (reduction of more than 50\% of the wound area). Clinical conditions improved significantly in 7 of the 20 cases treated with Cutimed ${ }^{\mathrm{TM}}$ Sorbact $^{\mathrm{TM}}(35 \%$ responder patients, $77.49 \%$ average reduction of the area), with complete healing in 2 cases. In another 8 cases general improvement of the wound conditions were observed, even if the wound area decreased less than 50\% (average $38.33 \%$ reduction). In 1 case the wound area showed no variation and in the remaining 4 cases there was an increase $(34.48 \%$ mean increase of the area). Table 1 shows the results of wound reduction in each patient, in comparison with the quantitation of bioburden and bacterial presence.

Bacterial load in chronic wounds

Quantification of the total bacterial load was assessed by comparison with a standard curve obtained by 10 -fold serially diluted purified DNA of E. coli.

Reactions were performed on $100 \mathrm{ng}$ of total DNA from biopsies, amplifying simultaneously both the highly conserved bacterial 16S rRNA gene and the eukaryotic RNaseP gene, used as an internal control for assessment.

In the case of swabs, reactions were performed on $100 \mathrm{ng}$ of extracted DNA amplifying the bacterial $16 \mathrm{~S}$ rRNA gene, and the results were normalised to the total volume of extraction buffer.

The average bacterial load in normal healthy skin was $4.5 \times 10^{5}$ bacteria per swab, representing the normal flora. 
Table 1 Summary of results obtained for each patient

\begin{tabular}{|c|c|c|c|c|c|c|c|c|c|}
\hline \multirow[t]{2}{*}{ Patients } & \multirow[t]{2}{*}{$\begin{array}{l}\Delta \text { Area } \\
(\%)^{\mathrm{a}}\end{array}$} & \multirow[t]{2}{*}{$\begin{array}{l}\Delta \text { Total bacterial load } \\
\text { (biopsies) }(\%)^{\mathrm{b}}\end{array}$} & \multirow[t]{2}{*}{$\begin{array}{l}\Delta \text { Total bacterial } \\
\text { load (swabs) }(\%)^{\mathrm{b}}\end{array}$} & \multirow[t]{2}{*}{$\begin{array}{l}\Delta \text { Bacteroides load } \\
\text { (biopsies) }(\%)^{\mathrm{c}}\end{array}$} & \multirow[t]{2}{*}{$\begin{array}{l}\Delta \text { Fusobacterium load } \\
\text { (biopsies) }(\%)^{\mathrm{c}}\end{array}$} & \multicolumn{2}{|c|}{$\begin{array}{l}\text { Staphylococcus } \\
\text { (biopsies) }^{\mathrm{d}}\end{array}$} & \multicolumn{2}{|c|}{$\begin{array}{l}\text { Pseudomonas } \\
\text { (biopsies) }^{\mathrm{d}}\end{array}$} \\
\hline & & & & & & First & Last & First & Last \\
\hline 1 & -100 & -100 & -99.96 & -100 & - & - & - & - & - \\
\hline 2 & -50 & -99.98 & +73.33 & -99.99 & - & + & + & + & + \\
\hline 3 & -100 & -100 & -99.08 & - & - & - & - & - & - \\
\hline 4 & -90 & -99.68 & +70.93 & - & - & - & - & - & - \\
\hline 5 & -71.4 & -99.17 & -84.45 & -99.998 & - & + & - & - & - \\
\hline 6 & -40 & -98.28 & -73.35 & -100 & - & + & - & - & - \\
\hline 7 & -42.6 & -91.45 & -91.69 & - & - & + & - & - & - \\
\hline 8 & -34.6 & -92.09 & +36.51 & - & - & - & - & - & - \\
\hline 9 & -21.3 & -87.85 & +99.82 & +57.33 & - & - & - & - & + \\
\hline 10 & -46.3 & -85.53 & -50.6 & -85.32 & -100 & + & + & - & - \\
\hline 11 & +5.8 & +98.22 & -99.98 & +36.09 & - & + & + & - & - \\
\hline 12 & +72.7 & +19.13 & -99.74 & - & - & - & - & - & - \\
\hline 13 & +58.3 & +41.06 & +62.84 & - & - & + & + & - & - \\
\hline 14 & -0.5 & -97.66 & +92.93 & -99.83 & - & - & - & + & - \\
\hline 15 & +1.1 & -27.29 & +43.08 & +94.43 & - & - & - & - & - \\
\hline 16 & -44.7 & +95.53 & -77.97 & +83.33 & - & + & + & + & + \\
\hline 17 & -64.3 & -43.81 & +99.98 & - & - & + & - & - & - \\
\hline 18 & -33.3 & +11.48 & +99.82 & - & - & + & - & - & - \\
\hline 19 & -43.8 & +24.49 & +99.63 & - & -70 & + & + & - & - \\
\hline 20 & -66.7 & +80.4 & -99.72 & - & - & - & + & - & - \\
\hline
\end{tabular}

${ }^{\text {a }} \Delta$ Area shows the decrease (negative value) or the increase (positive value) in wound area at the end of the study, compared with the beginning, expressed as a percentage

${ }^{\mathrm{b}} \Delta$ Total bacterial load shows the decrease (negative value) or the increase (positive value) in total bacterial load at the end of the study, compared with the beginning, as determined by panbacterial real-time PCR. Values are expressed as percentages, in biopsies and swabs respectively

${ }^{\mathrm{c}} \Delta$ Bacteroides and Fusobacterium load show the percentage decrease (negative value) or the increase (positive value) in bacterial load at the end of the study compared to the beginning, as determined by specific real-time PCR

${ }^{\mathrm{d}}$ Columns labelled Staphylococcus and Pseudomonas show the presence of these germs in first and last biopsies as determined by conventional culture methods

The results are shown in Table 1, comparing for each sample the variation in bacterial load and wound reduction, during the 4 weeks of treatment with Cutimed ${ }^{\mathrm{TM}}$ Sorbact ${ }^{\mathrm{TM}}$.

According to the results, the samples can be divided into three groups. The first group is formed by samples where the positive clinical outcome is concordant with molecular data. In particular, 10 out of 15 wounds $(66 \%)$ with a positive clinical outcome and with $58 \%$ mean reduction of the wound's area, showed a significant decrease in the total bacterial load. The initial bacterial load was considerably different in the samples, ranging from $4.38 \times 10^{3}$ to $2.44 \times 10^{8}$ bacterial genomes $/ \mathrm{mg}$ of tissue. Nevertheless, the average of the total bacterial load at the beginning of treatment was $4.41 \times 10^{7} / \mathrm{mg}$ of tissue, and at the end decreased to $1.73 \times \mathrm{S} 10^{5} / \mathrm{mg}$ of tissue, corresponding to a 254 -fold decrease in the total bacterial load (Fig. 1). The decrease in bacterial load was statistically significant $(p=0.0243)$.
The analysis of swabs from the same wounds, collected once a week for 4 weeks, showed less variability among samples from different patients. The majority of specimens yielded over $10^{9}$ total bacteria at the initial sampling. Analysis of subsequent time points failed to show any significant decrease. In fact, in spite of clinical positive outcome, the bacterial load remained constantly high, ranging from $2.63 \times 10^{10}$ in the first samples to $9.37 \times 10^{9}$ bacterial genomes/swab in the final samples (Fig. 1).

The second group is formed by five chronic wounds with a negative clinical course, no response to treatment, and averaged a $27 \%$ increase in the wound area. The total bacterial load of biopsies showed a non-significant 5.2-fold decrease at the end of the treatment $\left(2.73 \times 10^{6}\right.$ to $5.22 \times 10^{5}$ bacterial genomes/mg of tissue; $p=0.6$; Fig. 1). Also, the swabs from these five cases did not show any significant change in bacterial load throughout the 4-week period of the study (Fig. 1). 
Fig. 1 Total bacterial load determined by panbacterial realtime PCR in biopsies and in swabs. Samples from patients have been grouped according to the clinical outcome. a Average bacterial load in biopsies with concordant clinical and molecular results. b Average bacterial load in corresponding swabs. c Average bacterial load in biopsies with a positive clinical result, but no significant decrease in average bacterial load. d Average bacterial load in corresponding swabs. e Average bacterial load in biopsies that did not have a positive clinical result. f Average bacterial load in corresponding swabs

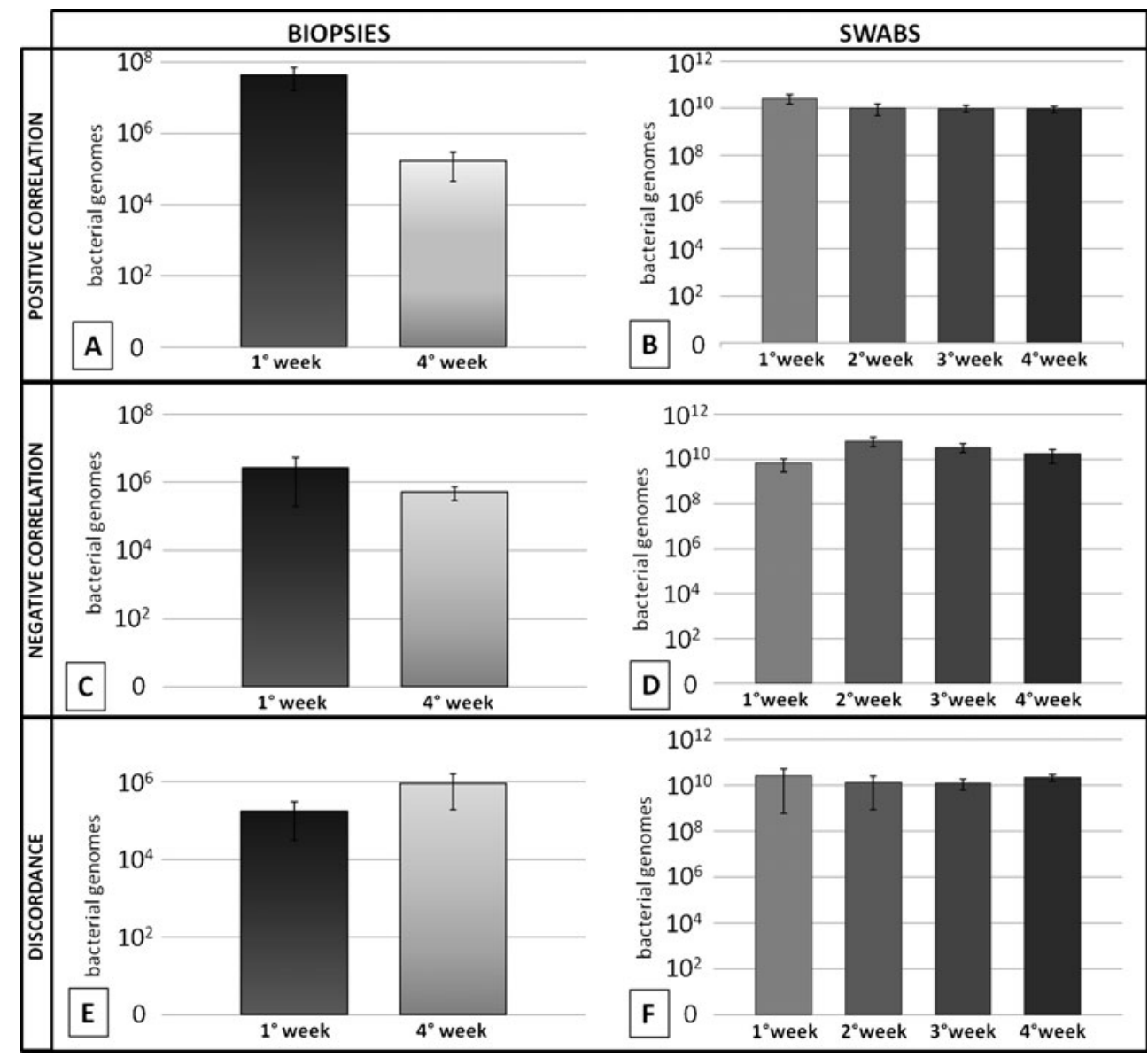

The last group of samples comprises five chronic wounds with a positive clinical outcome (average 50\% decrease in the affected area), but no reduction in the total bacterial load in biopsies. In fact, a slight, non-significant 5.3-fold reduction was recorded ( $p=0.75$; Fig. 1 ). Similarly, the total bacterial load in swabs did not change during treatment (Fig. 1).

Search for specific bacterial species in chronic wounds

Biopsies from chronic wounds were analysed using classical culture methods by plating on selective agar for the detection of $S$. aureus and P. aeruginosa. The colony count in the normal healthy skin was under $100 \mathrm{CFU}$. The results are summarised in Table 1. S. aureus was detected in 10 out of 20 biopsies at the beginning of the study, and persisted in 7 cases. P. aeruginosa was detected in 3 samples both in the initial and the final biopsies. As shown in Table 1, there was no correlation with the clinical outcome, nor with the results of panbacterial real-time PCR. For example, patient 1 had a complete clinical recovery, with a marked decrease in bacterial load by qPCR, in the complete absence of $S$. aureus and P. aeruginosa in both biopsies. By contrast, patient 2 had a significant clinical outcome and a corresponding decrease in bacterial load, with the presence of higher than normal loads of $S$. aureus and $P$. aeruginosa, both in the first and in the last biopsy.

We also searched using real-time PCR for the specific presence of Fusobacterium and Bacteroides species, two anaerobe bacteria frequently detected in chronic wounds. Sensitivity of reaction, and standard curve were determined in serial dilutions of genomic DNA and plasmids containing the amplified region of Fusobacterium and Bacteroides. Both reactions were sensitive enough to detect as few as 100 total genomes. No cross-reaction between primer and probe sets was observed, and no amplification of eukaryotic cell DNA and other bacterial DNA was present using these sets of primers. The linear range of amplification was achieved from $10^{3}$ to $10^{7}$ total molecules (data not shown).

Bacteroides was found in 10 out of 20 wounds $(50 \%)$. Bacteroides load averaged $8 \times 10^{7}$ genomes $/ \mathrm{mg}$ of tissue in the first biopsy, and $4 \times 10^{5}$ in the final biopsy, showing a 197-fold decrease after treatment with Cutimed ${ }^{\mathrm{TM}}$ Sorbact $^{\mathrm{TM}}$ with no statistical difference between the first and last biopsy $(p=0.1)$. In particular, with the exception of two samples where Bacteroides disappeared after Cutimed $^{\mathrm{TM}}$ Sorbact ${ }^{\mathrm{TM}}$ treatment, all cases positive in the first biopsy were also positive in the final biopsy.

More specifically, the presence of Bacteroides DNA was irrespective of the clinical outcome, being present in 6 
wounds belonging to the first group of samples (positive correlation between total bacterial load and clinical outcome), in 3 wounds of the second group (absence of positive clinical result) and in 1 wound of the third group of samples (positive clinical result with no decrease in total bacterial load).

Fusobacterium DNA was found in 2 out of 20 wounds $(10 \%)$. The initial load was $1.7 \times 10^{4}$ genomes $/ \mathrm{mg}$ of tissue, and the load showed a non-significant 3.5-fold decrease $\left(4.9 \times 10^{3}\right.$ genomes $\left./ \mathrm{mg}\right)$ after treatment with Cutimed ${ }^{\mathrm{TM}}$ Sorbact ${ }^{\mathrm{TM}}$.

\section{Discussion}

This work aimed for the first time to verify the suitability of real-time PCR quantification of total bacterial load as a quick and sensitive laboratory parameter. To achieve the goal, a panbacterial real-time PCR based on amplification of a conserved region of the $16 \mathrm{~S}$ gene was set up, and verified on the genome of six different bacteria. The results show that this approach is sensitive and allows precise quantification over a broad range of concentrations (from 100 to $10^{7}$ target molecules). Subsequently, this method of analysis was applied in the course of a pilot study on the use of Cutimed ${ }^{\mathrm{TM}}$ Sorbact ${ }^{\mathrm{TM}}$, a membrane with hydrophobic properties that binds and retains bacteria, for treatment of chronic wounds.

The clinical results show that Cutimed $^{\mathrm{TM}}$ Sorbact $^{\mathrm{TM}}$ treatment resulted in complete success of the therapy in 7 out of 20 patients, and a general improvement in another 9 patients, even if the reduction of wound area was less than $50 \%$. This positive outcome has to be evaluated considering that the wounds selected were persistent and resistant to other therapeutic options.

The laboratory results on panbacterial real-time PCR show that the total bacterial load significantly decreased in 10 out of 15 healing chronic wounds and did not change in 5 out of 5 non-healing chronic wounds. Furthermore, bacterial load decreased in biopsies, but not in swabs. Classical microbiology for two aerobes widely predominant in chronic wounds (S. aureus, P. aeruginosa) did not show any correlation with the clinical outcome of the therapy. Also, molecular quantification for two anaerobes often implicated in chronic wounds (Bacteroides spp., Fusobacterium spp.) did not show any correlation with the clinical outcome.

Several observations arise from this study. The first shows that panbacterial real-time PCR is a reliable method of assessing the therapeutic success of chronic wound treatment. In fact, 10 out of 15 chronic wounds with complete or partial therapeutic success showed a significant decrease in total bacterial load, and no decrease was observed in 5 out of 5 wounds with no clinical improvement. In total, the results of real-time PCR were concordant with clinical results in 15 out of 20 chronic wounds, indicating that total bacterial load might be considered as a useful biomarker for treatment prognosis. The scientific literature highlights the need for prognostic indicators of chronic ulcers. A recent review enumerates several potential biomarkers (cytokines, proteases and their inhibitors, senescence markers, oxidative stress, microbiological status, etc.), but concludes that no available data reflect wound progression or regression [22]. Our study indicates that panbacterial real-time PCR might fill this need.

Another observation is that quantitation studies of chronic wounds by panbacterial real-time PCR requires analysis of biopsies. In fact, no significant result was obtained by analysis of swabs. Even if this result cannot be explained at this time, there are several reports indicating that swab analysis gives inconsistent results [23]. The Centers for Disease Control recommend either tissue biopsy or fluid aspiration methods to determine the bacterial content of wounds [24, 25]. It is possible that chronic wounds, even at an advanced stage of healing, are still colonised by a high number of bacteria at the surface, while infection of deep tissues has been eliminated. According to this hypothesis, positive bacterial swabs would indicate just the presence of colonising bacteria, while infectious processes are being eliminated.

Our results show that the analysis of specific pathogens, even using molecular techniques, is much less effective than panbacterial real-time PCR, and could even be misleading. In fact, by conventional culture $S$. aureus and $P$. aeruginosa were not detected in sample number 12 (Table 1), and yet this lesion was refractory to treatment and showed a substantial increase in the wound area. Furthermore, both bacteria continued to be present in sample number 2, even if this lesion responded well to the therapy with a significant decrease in the affected area, and a consistent decrease in the bacterial load. A similar situation was detected by analysis of anaerobes by real-time PCR. No significant decrease in Bacteroides spp. was recorded in healing wounds, and this anaerobic bacteria had similar loads in healing and non-healing lesions (Table 1).

At the moment it is not possible to explain with convincing arguments the fact that five chronic wounds showed a positive clinical outcome with no decrease in total bacterial burden. Plausible explanations are that the bacterial population in these wounds was only a minor pathogenic component, or that the presence of bacteria reflected colonising, but not infecting micro-organisms. Alternatively, it is possible that these five lesions showed a fungal or yeast component [26] that was removed by the dressing. Another possible explanation is that there was a switch in the composition of the bacterial population, and 
that more aggressive bacteria present in the first biopsy had been replaced in the last biopsy by commensal microorganisms. However, it should be noted that $S$. aureus, $P$. aeruginosa and Bacteroides spp. were not involved in this hypothetical process.

In conclusion, despite the small number of samples analysed, these results show that panbacterial qPCR is a promising, quick method of determining the total bacterial load in chronic wounds, and suggest that it might be an important biomarker for the prognosis of chronic wounds under treatment.

Acknowledgements The technical assistance of AnnaLisa Peverati is gratefully acknowledged. We thank Linda Marie Sartor for revision of the English manuscript. This work was supported in part by a FAR grant from the University of Ferrara.

Open Access This article is distributed under the terms of the Creative Commons Attribution Noncommercial License which permits any noncommercial use, distribution, and reproduction in any medium, provided the original author(s) and source are credited.

\section{References}

1. Gjodsbol K, Christensen JJ, Karlsmark T, Jorgensen B, Klein BM, Krogfelt KA (2006) Multiple bacterial species reside in chronic wounds: a longitudinal study. Int Wound J 3:225-231

2. Frank DN, Wysocki A, Specht-Glick DD, Rooney A, Feldman RA, St. Amand AL, Pace NR, Trent JD (2009) Microbial diversity in chronic open wounds. Wound Repair Regen 17:163-172

3. Brook I, Frazier EH (1998) Aerobic and anaerobic microbiology of chronic venous ulcers. Int J Dermatol 37:426-428

4. Howell-Jones RS, Wilson MJ, Hill KE, Howard AJ, Price PE, Thomas DW (2005) A review of the microbiology, antibiotic usage and resistance in chronic skin wounds. J Antimicrob Chemother 55:143-149

5. Bowler PG, Duerden BI, Armstrong DG (2001) Wound microbiology and associated approaches to wound management. Clin Microbiol Rev 14:244-269

6. Bowler PG, Davies BJ (1999) The microbiology of infected and noninfected leg ulcers. Int J Dermatol 38:573-578

7. Madsen SM, Westh H, Danielsen L, Rosdahl VT (1996) Bacterial colonisation and healing of venous leg ulcers. APMIS 104:895899

8. Wolcott RD, Dowd SE (2008) A rapid molecular method for characterising bacterial bioburden in chronic wounds. J Wound Care 17:513-516

9. Thomsen TR, Aasholm MS, Rudkjøbing VB, Saunders AM, Bjarnsholt T, Givskov M, Kirketerp-Møller K, Nielsen PH (2010) The bacteriology of chronic venous leg ulcer examined by culture-independent molecular methods. Wound Repair Regen $18: 38-49$
10. Martin JM, Zenilman JM, Lazarus GS (2010) Molecular microbiology: new dimensions for cutaneous biology and wound healing. J Invest Dermatol 130:38-48

11. Hill KE, Davies CE, Wilson MJ, Stephens P, Harding KG, Thomas DW (2003) Molecular analysis of the microflora in chronic venous leg ulceration. J Med Microbiol 52:365-369

12. Fang H, Hedin G (2003) Rapid screening and identification of methicillin-resistant Staphylococcus aureus from clinical samples by selective-broth and real-time PCR assay. J Clin Microbiol 41:2894-2899

13. Boutaga K, van Winkelhoff AJ, Vandenbroucke-Grauls CMJE, Savelkoul PHM (2005) Periodontal pathogens: a quantitative comparison of anaerobic culture and real-time PCR. FEMS Immunol Med Microbiol 45:191-199

14. Wilson KH, Blitchington RB, Greene RC (1990) Amplification of bacterial 16S ribosomal DNA with polymerase chain reaction. J Clin Microbiol 28:1942-1946

15. Davies CE, Hill KE, Wilson MJ, Stephens P, Hill CM, Harding KG, Thomas DW (2004) Use of 16 S ribosomal DNA PCR and denaturing gradient gel electrophoresis for analysis of the microfloras of healing and nonhealing chronic venous leg ulcers. J Clin Microbiol 42:3549-3557

16. Doyle RJ, Rosenberg M (eds) (1990) Microbial cell surface hydrophobicity. ASM, Washington DC

17. Ljungh A, Wadström $\mathrm{T}$ (1995) Growth conditions influence expression of cell surface hydrophobicity of staphylococci and other wound infection pathogens. Microbiol Immunol 39:753-757

18. Ljungh A, Yanagisawa N, Wadström T (2006) Using the principle of hydrophobic interaction to bind and remove wound bacteria. J Wound Care 15:175-180

19. O'Meara S, Cullum N, Majid M, Sheldon T (2000) Systematic reviews of wound care management: (3) antimicrobial agents for chronic wounds; (4) diabetic foot ulceration. Health Technol Assess 4:1-237

20. Wright JB, Lam K, Burrell RE (1998) Wound management in an era of increasing bacterial antibiotic resistance: a role for topical silver treatment. Am J Infect Control 26:572-577

21. Yang S, Lin S, Kelen GD, Quinn TC, Dick JD, Gaydos CA, Rothman RE (2002) Quantitative multiprobe PCR assay for simultaneous detection and identification to species level of bacterial pathogens. J Clin Microbiol 40:3449-3454

22. Moore K, Huddleston E, Stacey MC, Harding KG (2007) Venous leg ulcer - the search for a prognostic indicator. Int Wound J 4:163-172

23. Donovan S (1998) Wound infection and wound swabbing. Prof Nurse 13:757-759

24. Rantakokko-Jalava K, Nikkari S, Jalava J, Eerola E, Skurnik M, Meurman O, Ruuskanen O, Alanen A, Kotilainen E, Toivanen P, Kotilainen P (2000) Direct amplification of rRNA genes in diagnosis of bacterial infections. J Clin Microbiol 38:32-39

25. Fenollar F, Roux V, Stein A, Drancourt M, Raoult D (2006) Analysis of 525 samples to determine the usefulness of PCR amplification and sequencing of the 16S rRNA gene for diagnosis of bone and joint infections. J Clin Microbiol 44:1018-1028

26. Dowd SE, Delton Hanson J, Rees E, Wolcott RD, Zischau AM, Sun Y, White J, Smith DM, Kennedy J, Jones CE (2011) Survey of fungi and yeast in polymicrobial infections in chronic wounds. J Wound Care 20:40-47 